\title{
Spatial scaling from latitudinal gradients: size-specific fecundity in the American lobster Homarus americanus
}

\author{
Jens J. Currie ${ }^{1, *}$, David C. Schneider ${ }^{2}$ \\ ${ }^{1}$ Department of Biology, Memorial University of Newfoundland, St. John's, Newfoundland A1C 5S7, PO Box 4200, Canada \\ ${ }^{2}$ Ocean Sciences Centre, Memorial University of Newfoundland, Marine Lab Road, St. John's, Newfoundland A1C 5S7, Canada
}

\begin{abstract}
Estimates of key population parameters are required to evaluate conservation or management measures, but are often available at only a few locations within the range of a species. We assembled all available estimates of a single parameter (fecundity as a function of size) in the lobster Homarus americanus to develop a large-scale model applicable throughout the species' range. In this species, a 2-parameter power function, $F=a L^{b}$, is used to describe the relationship of fecundity $F$ to carapace length $L$. There was a well-defined latitudinal gradient in the allometric (power law) exponent $b$, with the smaller values at the northern end of the species' range. The allometric exponent $b$ decreased at a rate of $8.6 \%$ per degree of latitude, from southern New England to the northern end of the range (Newfoundland). The scaling factor a increased at a rate of 491 eggs per degree of latitude, as estimated at a carapace length of $85 \mathrm{~mm}$. Fecundity can be estimated from this large-scale model at any location throughout much of the species' range. Data archiving allows re-estimation of parameters when better methods become available, and also allows large-scale models of population parameters to be developed.
\end{abstract}

KEY WORDS: American lobster $\cdot$ Fecundity $\cdot$ Statistical model $\cdot$ Egg production $\cdot$ Management Conservation

\section{INTRODUCTION}

Fecundity is a key population parameter in the management of many commercially important species. For these species, population fecundity is typically estimated from the size distribution or from the size-at-age distribution. In the American lobster Homarus americanus, these relationships predict fecundity from carapace length and form an empirical foundation for the estimation of life history patterns, development of egg per recruit models, population growth, and evaluation of management measures (FRCC 2007, ASMFC 2009). Fecundity estimates in this species have been developed at locations throughout much of the commercial range, from northern Newfoundland to southern New England
(Herrick 1896, Saila et al. 1969, Squires 1970, Perkins 1971, Squires et al. 1974, Aiken \& Waddy 1980, Ennis 1981, Campbell \& Robinson 1983, Attard \& Hudon 1987, Estrella \& Cadrin 1995). These estimates are driven by the need for population-scale monitoring of vital rates in a fishery where annual exploitation rates at legal size are rarely below $80 \%$, rising to $95 \%$ (FRCC 2007, ASMFC 2009) in some lobster fishing areas in Newfoundland. More recently, the need for fecundity estimates has been driven by research on the efficacy of conservation measures, such as v-notching (e.g. Daniel et al. 1989) and marine protected areas (Estrella \& Cadrin 1995). Fecundity, as it is defined for this species, is the rate of egg release per year in those females that show eggs on the abdomen. Lobsters typically release eggs every other 
year, but this schedule changes with size (Campbell \& Robinson 1983).

Variability in size-fecundity relationships is well recognized in lobsters (Estrella \& Cadrin 1995) and has been attributed to differences in experimental methods, geography and/or sample size (Aiken \& Waddy 1980, Estrella \& Cadrin 1995). Aiken \& Waddy (1980) emphasize the need for better estimates based on standard methodologies and increased sample size. However, large sampling studies are becoming less feasible because of conservation measures in response to increased fishing effort and economic value (Estrella \& Cadrin 1995). Co-management of the species limits the availability of permits that allow for the removal of eggs from more than a small number of females. This presents the challenge of assessing a population at any one location using size-fecundity equations of unknown applicability from elsewhere in the species' range.

The large-scale applicability of available sizefecundity relationships for Homarus americanus is additionally compromised by the uncorrected bias of log-transformed equations (Estrella \& Cadrin 1995). Size-fecundity relationships are typically 2-parameter power functions (Ennis 1981, Campbell \& Robinson 1983, Estrella \& Cadrin 1995). They are not estimated on their original, arithmetic scale, but are transformed into their logarithmic equivalent and displayed as a bivariate plot with a straight line fitted by the method of least squares (Ennis 1981, Campbell \&

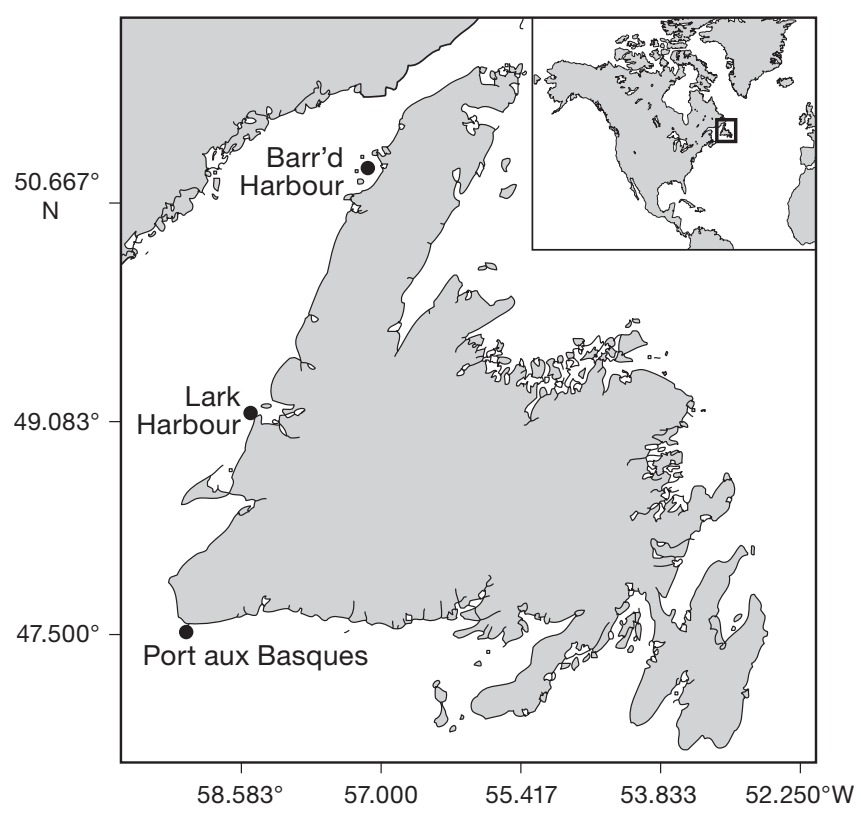

Fig. 1. The 3 Homarus americanus sampling locations on the west coast of Newfoundland, Canada
Robinson 1983, Estrella \& Cadrin 1995). This approach allows investigators to readily compare results, but it introduces bias (Smith 1984, 1993, Packard 2009) that compromises the predictive power of the relationship (Zar 1968, Smith 1980, 1984). Bias associated with log transformations includes the magnification of the effects of outliers (Smith 1980, 1984), multiplicative error (Smith 1993) and inaccurate estimates of the dependent variable at large values of the independent variable (Packard \& Boardman 2008).

The objectives of the present study were to: (1) reestimate size-fecundity relationships free of bias due to log transformation; (2) quantify geographic variation in size-fecundity relationships throughout the Northwest Atlantic; and (3) develop a large-scale model to estimate size-fecundity parameters $a$ and $b$ from latitude $\left({ }^{\circ} \mathrm{N}\right)$ at any location within the commercial range.

\section{MATERIALS AND METHODS}

\section{Study area and data collection}

Between 3 and 19 June 2009, a total of 37 ovigerous (egg-bearing) female Homarus americanus were sampled from commercial lobster traps in 3 regions along the west coast of Newfoundland (Fig. 1): Barr'd Harbour ( $\mathrm{n}=12)$, Lark Harbour $(\mathrm{n}=11)$ and Port aux Basques $(n=14)$. Because of regulatory restrictions on numbers collected for egg estimates, lobsters were collected only if they were outside the size range (i.e. $>105 \mathrm{~mm}$ or $<82.5 \mathrm{~mm}$ ) of previous estimates from Newfoundland (Ennis 1981). The effects of removing fecundity values within 82.5 and $105 \mathrm{~mm}$ carapace length (CL) on estimates of parameters $a$ and $b$ were tested on a larger data set to ensure that the absence of these values for the Newfoundland data had no significant effect. Estimates of parameters $a$ and $b$ were computed with and without data between 82.5 and $105 \mathrm{~mm} \mathrm{CL}$, and the resultant parameters were tested for significant differences using an ANOVA.

Fecundity was defined as the total number of eggs the female was carrying externally at the time of sampling. Immediately following capture, the carapace length was measured and the eggs were removed and fixed in a $5 \%$ formalin-seawater solution, consistent with previous work on this species (Perkins 1971, Ennis 1981, Campbell \& Robinson 1983, Attard \& Hudon 1987). Before releasing the female, eggs remaining attached to the abdomen were counted for inclusion in the final fecundity estimate. 
After fixation, eggs were removed from formalin, rinsed in freshwater and spread thinly over shallow glass Petri dishes to dry at $50^{\circ} \mathrm{C}$ for $20 \mathrm{~h}$ (Attard \& Hudon 1987). The dried eggs were rubbed over a fine screen mesh netting $(250 \mu \mathrm{m})$ to remove any excessive connective tissue and weighed to the nearest $0.0001 \mathrm{~g}$. Fecundity was determined by counting 5 weighed sub-samples ( $\geq 30$ eggs sample $^{-1}$ ) and dividing the mass of an average egg by the mass of the entire egg mass. These counts were validated by comparing them with 4 counted samples; the error ranged from 0.09 to $0.90 \%$ (mean $=0.54 \%$ ).

\section{General model and data analysis}

Fecundity value per female for 5 sites in Newfoundland (Ennis 1981), 3 sites in the Canadian Maritimes (Campbell \& Robinson 1983) and 3 sites in New England (Estrella \& Cadrin 1995) were provided by the authors of the these studies. Fecundity per female for Barr'd Harbour, Lark Harbour and Port aux Basques was estimated from samples taken at each location. The data were fitted to a 2-parameter power function (Eq. 1) using nonlinear (weighted) least-squares regression to avoid the bias of log transformations (Smith 1984, 1993, Packard 2009), where the weights were based upon the variance at each location:

$$
F=a L^{b}
$$

where $F$ is fecundity, $a$ is a scaling factor, $L$ is the carapace length and $b$ is a power law exponent. The newly estimated parameters $a$ and $b$ were used to develop the general latitude model. Parameter estimates were reported with 4 or 5 significant figures, recognizing the sensitivity of estimates of $F$ to small variations in $b$, and recognizing that estimates of $F$ are only correct to 2 or 3 significant figures.

In order to increase size range and sample size, nearby locations were tested for homogeneity among slopes and intercepts and combined if no significant differences were found. Intercepts and slopes were calculated using non-linear regression analysis, and significance tests were completed using ANOVA. Size-fecundity data for 2 locations with small size ranges and similar latitudes were combined and estimates of the slope and intercept were determined using non-linear regression analysis regardless of location. This produced a single estimate for the slope and intercept. A second nonlinear regression analysis was then carried out specifying different estimates for the slope and the intercept based on location, producing 2 estimates for slope and intercept. The 2 non-linear models were then tested for differences using an ANOVA. If the 2 models were found to be significantly different ( $p<0.05$ ), the conclusion was made that accounting for location had a significant effect on the estimates of the slope and intercept, and the 2 locations were not combined. If the 2 models were not significantly different $(p>0.05)$, the conclusion was made that location had no significant effect on estimates of the slope and intercept and, therefore, the 2 locations were combined to increase the size range and sample size.

Latitude for each location was obtained from the publication if present, or from a map if not stated. The average latitude was used where locations were combined. Latitude $\left({ }^{\circ} \mathrm{N}\right)$ was then converted into decimal degrees to aid in graphical analysis.

The general latitude model was then formulated using the following 3 equations. The relationship between the parameter $b$ and latitude was estimated using the following equation:

$$
b=m_{1} \text { Lat }+g_{1}
$$

where $b$ is the power law exponent from Eq. (1) for those data sets that had large size ranges (see Table 2), $m_{1}$ is the slope, Lat is latitude and $g_{1}$ is the intercept.

The relationship between parameter $a$ and latitude was calculated in 2 steps. First, the mean fecundity at a single carapace length (85 $\mathrm{mm})$ was calculated from latitude using the following formula:

$$
F_{85}=m_{2} \text { Lat }+g_{2}
$$

where $F_{85}$ is the mean fecundity at $85 \mathrm{~mm}$ carapace length, obtained by averaging the fecundity observed at $85 \mathrm{~mm}$ carapace length (only data sets containing egg counts at $85 \mathrm{~mm}$ CL were used in this step), $m_{2}$ is the slope, Lat is the latitude and $g_{2}$ is the intercept. A carapace length of $85 \mathrm{~mm}$ was used because it was the size class available at most locations and provided the largest sample size to develop Eq. (3).

Second, mean fecundity, carapace length and parameter $b$ were then substituted into the following equation to solve for parameter $a$ :

$$
a=F_{85} /\left(L^{b}\right)
$$

where $a$ is the scaling factor in Eq. (1), $F_{85}$ is the mean fecundity obtained from Eq. (3), $L$ is $85 \mathrm{~mm}$ and $b$ is the power law exponent obtained from Eq. (2).

The general latitude model was checked for bias by comparing the fecundity values predicted by the model with the observed values. The observed values of fecundity were calculated by dividing cara- 
pace lengths for a given location into $5 \mathrm{~mm}$ size classes and averaging the egg counts within each size class. These counts were then averaged to determine a single observed value for each location. The predicted values of fecundity for each of the different models/equations (see Table 4) were determined by substituting the mean of each $5 \mathrm{~mm}$ size class, for any one location, into the equation for that region or the equation developed using the general latitude model. These predicted values of fecundity for each size class were then averaged to determine a single observed value for each location. The bias for each model/equation was calculated as the difference between the observed and predicted values of fecundity. Paired $t$-tests were used to test whether bias differed significantly from zero. Residual versus fit and quantile-quantile plots of the residuals were used to evaluate assumptions for computing p-values. All the analyses met the assumptions of homogeneity and normally distributed residuals. The criterion for statistical significance was a Type I error ( $p$-value) of less than $5 \%$.

\section{RESULTS}

\section{Newfoundland fecundity models}

ANOVA showed no significant difference in the estimates of parameters $a$ and $b$ when data between 82.5 and $105 \mathrm{~mm}$ CL were included or excluded $\left(F_{1,6174}=0.334, \mathrm{p}=1.0\right)$.

Analysis of size-fecundity relationships with nonlinear regression (Table 1) showed Port aux Basques to have a steeper slope than more northerly sites (Lark Harbour and Barr'd Harbour), which displayed similar slopes (Fig. 2). Extra-sum-of-squares F-tests (Motulsky \& Christopoulos 2004) were carried out to evaluate differences in the slopes and intercepts of the size-fecundity relationships from the west coast of Newfoundland. Slopes and intercepts for Barr'd

Table 1. Parameters $a$ and $b$ for size-fecundity relationships of Homerus americanus on the west coast of Newfoundland

\begin{tabular}{|c|c|c|c|c|c|}
\hline Site & Latitude $\left({ }^{\circ} \mathrm{N}\right)$ & $\mathrm{n}$ & a & $b$ & $\mathrm{r}^{2}$ \\
\hline Barr'd Harbour & 50.8497 & 12 & 0.0600 & 2.7703 & 0.9796 \\
\hline Lark Harbour & 48.9743 & 12 & 0.0399 & 2.8564 & 0.9849 \\
\hline Port aux Basques ${ }^{\mathrm{a}}$ & 47.6606 & 9 & 0.0063 & 3.2652 & 0.9465 \\
\hline
\end{tabular}

Harbour and Lark Harbour did not differ significantly $\left(F_{1,20}=0.707, \mathrm{p}=0.145\right)$ and were combined to produce the following equation (Fig. 3):

$$
F=0.04852 L^{2.815}
$$

\section{General model}

A preliminary analysis showed that locations with a limited range in body size produced unrealistic estimates of the parameter $b$. To develop a general model, data sets with large size ranges were needed to ensure that estimates of parameters $a$ and $b$ were

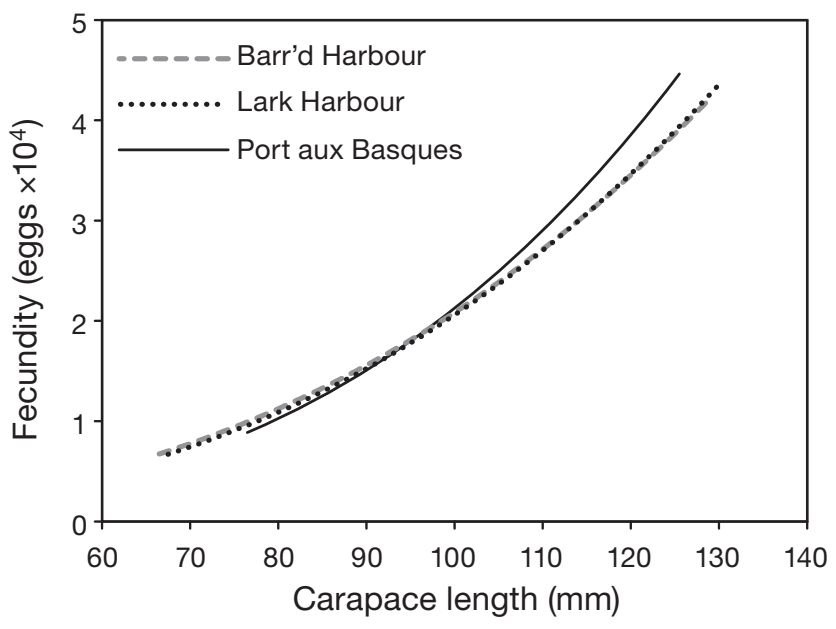

Fig. 2. Homarus americanus. Size-fecundity relationships for American lobster on the west coast of Newfoundland. Barr'd Harbour: $\mathrm{r}^{2}=0.98$, SE on slope \pm 0.1789 ; Lark Harbour: $\mathrm{r}^{2}=$ 0.98, SE \pm 0.1431 ; Port aux Basques: $\mathrm{r}^{2}=0.95$, $\mathrm{SE} \pm 0.4056$

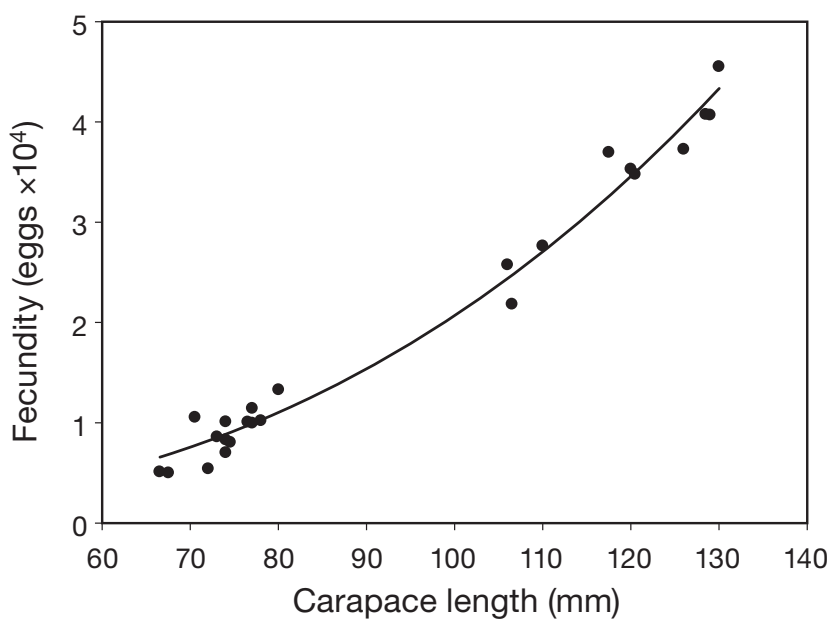

Fig. 3. Homarus americanus. Combined size-fecundity relationships of American lobster for Barr'd Harbour and Lark Harbour on the west coast of Newfoundland. $r^{2}$ : 0.98, SE on slope: \pm 0.1092 
Table 2. Size-fecundity parameters $a$ and $b$ for sites used to graph the latitude variation in size-fecundity relationships of the American lobster Homarus americanus

\begin{tabular}{|lcccc|}
\hline Site & Size range $(\mathrm{mm})$ & Latitude $\left({ }^{\circ} \mathrm{N}\right)$ & $a$ & $b$ \\
\hline Buzzards Bay and Outer Cape Cod, Massachusetts & $71-143$ & 41.650 & 0.003 \\
Southern Gulf of Maine, Massachusetts & $72-137$ & 42.200 & 0.001 & 3.368 \\
Northumberland Strait and Bay of Fundy, Nova Scotia & $65-163$ & 44.962 & 0.007 & 3.188 \\
Paradise, Newfoundland & $75-139$ & 47.446 & 0.053 \\
Barr'd Harbour and Lark Harbour, Newfoundland & $67-130$ & 49.912 & 0.049 \\
\hline
\end{tabular}

representative of large size ranges. To increase range in body size, the locations with similar latitudes were tested for homogeneity among slopes and intercepts. Ship Harbour and Boswarlos $\left(F_{1,142}=\right.$ 4.483, $\mathrm{p}=0.036$ ) and Ship Harbour and Arnold's Cove $\left(F_{1,110}=5.756, \mathrm{p}=0.018\right)$ showed significant differences among slopes and intercepts, and were not

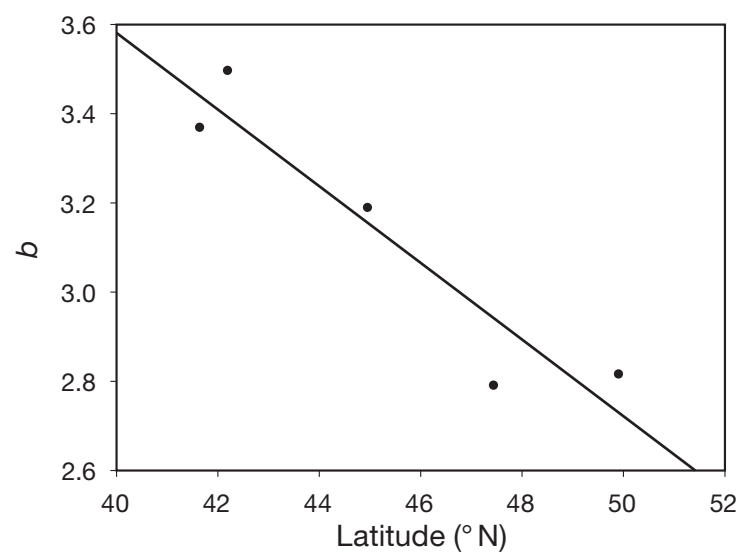

Fig. 4. Relationship between the power law exponent $b$ and latitude. $\mathrm{r}^{2}$ : 0.8845 , SE on slope: \pm 0.0179 per degree latitude

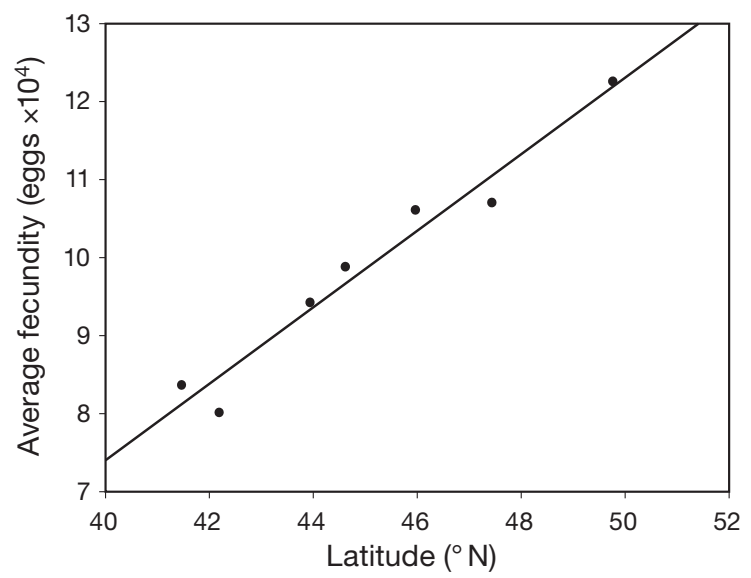

Fig. 5. Homarus americanus. Relationship between mean fecundity at $85 \mathrm{~mm}$ carapace length (CL) and latitude. $\mathrm{r}^{2}$ : 0.96, SE on slope: \pm 45.502 eggs per degree latitude. Note that mean fecundity at $85 \mathrm{~mm} \mathrm{CL}$ was only available for 7 locations included in the analysis because they had narrow size ranges. The following pairs, Northumberland Strait and the Bay of Fundy $\left(F_{1,123}=2.432, \mathrm{p}=0.122\right)$, Buzzards Bay and Outer Cape Cod $\left(F_{1,284}=2.079, \mathrm{p}=\right.$ $0.151)$, and Barr'd Harbour and Lark Harbour $\left(F_{1,23}=\right.$ 1.453, $\mathrm{p}=0.707$ ), all showed homogeneity among slopes and intercepts. As a result, these 6 data sets were combined into 3 , thus increasing their size range. The latitudes for each pair were averaged and new parameters were calculated (Table 2). Paradise and the southern Gulf of Maine were included in the analysis, as single locations, because they displayed large size ranges (Table 2).

\section{General latitude model}

The relationship between parameter $b$ and latitude was found to be (Fig. 4):

$$
b=-0.08597 \text { Lat }+7.0202
$$

The relationship between mean fecundity and latitude was found to be (Fig. 5):

$$
F_{85}=490.6 \text { Lat }-12222
$$

Parameter estimates for all locations and the development of the general latitude model were recalculated using bias-free non-linear regression and are recorded in Table 3.

\section{Validation of fecundity estimates obtained using the general latitude model}

Fecundity estimates obtained using the published parameter estimates (see 'Material and methods: General model and data analysis') and the parameter estimates developed using the general latitude model (Table 3) showed little bias relative to observed values, having biases of -5.2 and $-4.39 \%$, respectively (Table 4 ). Moreover, the mean differences in the observed values of fecundity and the 
Table 3. Comparisons of published parameter estimates $a$ and $b$ with estimates obtained using 2 different models/equations. Published equation data for Newfoundland are from Ennis (1981), for the Canadian Maritimes from Campbell \& Robinson (1983), and for New England from Estrella \& Cadrin (1995)

\begin{tabular}{|c|c|c|c|c|c|c|c|c|}
\hline \multirow{3}{*}{$\begin{array}{l}\text { Area } \\
\text { Newfoundland }\end{array}$} & \multirow{3}{*}{$\begin{array}{l}\text { Latitude } \\
\qquad\left({ }^{\circ} \mathrm{N}\right)\end{array}$} & \multirow{3}{*}{$\begin{array}{l}\text { Longitude } \\
\qquad\left({ }^{\circ} \mathrm{W}\right)\end{array}$} & \multirow{2}{*}{\multicolumn{2}{|c|}{$\begin{array}{cc}\text { General latitude model } \\
a & b\end{array}$}} & \multicolumn{2}{|c|}{ Nonlinear equation } & \multicolumn{2}{|c|}{ Published equation } \\
\hline & & & & & a & $b$ & a & $b$ \\
\hline & & & & & & & & \\
\hline Northwest coast & 49.77394 & 57.96355 & 0.062735 & 2.741098 & 0.293255 & 2.39308 & 0.398253 & 2.316141 \\
\hline Boswarlos & 48.59123 & 58.76011 & 0.038033 & 2.842776 & 0.001862 & 3.49668 & 0.021154 & 2.938735 \\
\hline Arnold's Cove & 47.76326 & 53.97529 & 0.026753 & 2.913957 & 0.002641 & 3.47012 & 0.004532 & 3.347062 \\
\hline Paradise & 47.44649 & 54.52217 & 0.023376 & 2.94119 & 0.05339 & 2.78993 & 0.012695 & 3.098418 \\
\hline Ship Harbour & 47.35000 & 53.48611 & 0.022433 & 2.949486 & 1.36201 & 2.10847 & 0.487866 & 2.318816 \\
\hline \multicolumn{9}{|l|}{ Canadian Maritimes } \\
\hline Northumberland Strait & 45.97569 & 63.65158 & 0.012459 & 3.067636 & 0.000542 & 3.77922 & 0.000048 & 4.320195 \\
\hline Eastern Nova Scotia & 44.62729 & 62.20684 & 0.006968 & 3.183559 & 0.000251 & 3.9592 & 0.000059 & 4.272524 \\
\hline Bay of Fundy & 43.94880 & 66.46136 & 0.005192 & 3.24189 & 0.007236 & 3.19005 & 0.003182 & 3.353501 \\
\hline \multicolumn{9}{|l|}{ New England } \\
\hline Southern Gulf of Maine & 42.19955 & 70.49931 & 0.002417 & 3.392274 & 0.001443 & 3.49574 & 0.000919 & 3.580220 \\
\hline Outer Cape Cod & 41.82260 & 69.86543 & 0.002047 & 3.424681 & 0.006338 & 3.21765 & 0.012754 & 3.062789 \\
\hline Buzzard's Bay & 41.47663 & 70.86590 & 0.001757 & 3.454424 & 0.000523 & 3.75921 & 0.000076 & 4.17506 \\
\hline
\end{tabular}

estimated values obtained using the published sizefecundity equations (for details see Table 3 ) differed significantly from zero (paired $t=-2.35$, df $=10, \mathrm{p}=$ $0.04)$, despite the low power of the test because of the low degrees of freedom. In contrast, the mean differences in the observed values of fecundity and the estimated values obtained using the general latitude model (paired $t=1.13, \mathrm{df}=10, \mathrm{p}=0.28$ ) were not significantly different from zero for a test with the same degrees of freedom.

Table 4. Bias associated with differing methods of fecundity estimations. Bias is the mean difference in egg count from observed values and estimated values (observed - estimated). Bias $\%$ is the mean percent change between observed values and expected values: [(observed expected)/estimated] $\times 100$. Data sources for published equations are given in Table 3 . Note that Herrick's (1896) data were not included because they used total length measurements

\begin{tabular}{|c|c|c|c|c|c|c|}
\hline \multirow[t]{2}{*}{ Location } & \multicolumn{2}{|c|}{ Published equation } & \multicolumn{2}{|c|}{ Latitude model } & \multicolumn{2}{|c|}{ Nonlinear } \\
\hline & Bias & Bias \% & Bias & Bias \% & Bias & Bias \% \\
\hline Southern Gulf of Maine, MA & -1344 & -8.97 & -1115 & -9.66 & -627 & -5.44 \\
\hline Buzzards Bay, MA & -1130 & -7.80 & 1070 & 9.73 & -606 & -4.82 \\
\hline Outer Cape Cod, MA & 1230 & 1.17 & 4550 & 15.68 & 990 & 1.59 \\
\hline Arnold's Cove, NL & -291 & -1.51 & -2306 & -14.45 & -342 & -1.39 \\
\hline Boswarlos, NL & 841 & 3.80 & -613 & -8.88 & 265 & 1.35 \\
\hline Northwest coast, NL & -2 & -9.2 & -557 & -10.74 & -46 & -9.05 \\
\hline Paradise, NL & -1245 & -4.25 & 2645 & 9.15 & -96 & -2.53 \\
\hline Ship Harbour, NL & -1203 & -3.53 & -397 & -2.99 & -842 & -4.02 \\
\hline Bay of Fundy, NS & -1850 & -5.92 & 1471 & 2.21 & -1434 & -6.21 \\
\hline Eastern Nova Scotia, NS & -1562 & -11.27 & 1866 & 7.37 & -1290 & -10.94 \\
\hline Northumberland Strait, NS & -1452 & -9.72 & 658 & 5.47 & -387 & -7.01 \\
\hline Mean & -728 & -5.20 & 661 & 4.39 & -401 & -4.41 \\
\hline
\end{tabular}

\section{DISCUSSION}

\section{Geographic variation in size-fecundity relationships}

As expected, the size-fecundity parameter $b$ (Fig. 4, Table 3 ) decreased by $8.6 \%$ per degree of latitude. Unexpectedly, the fecundity at a fixed size (85 mm CL) increased with latitude, at a rate of 491 eggs per degree of latitude. These estimates are free of the bias that attends log transformation (Packard 2009). Substitution of estimates from Eqs. (2) and (4) into Eq. (1) results in a largescale model of fecundity that can be applied through much of the commercial range of Homarus americanus.

The decrease in the allometric coefficient $b$ with increasing latitude is consistent with the expectation that water temperature is the major factor affecting annual egg production (Waddy \& Aiken 1991) and growth rate (Ennis 1980). The increase 
in egg number with increasing latitude, at a fixed size $(85 \mathrm{~mm})$, suggests the presence of age-related effects on egg number, given slower growth rates at higher latitudes. Little is known about agerelated effects on egg production, because age cannot be measured directly in this species. However, possible effects of age and experience on egg number include increased success in egg attachment and retention.

Our results are consistent with the hypothesis that fecundity, as a function of body size, varies with latitude because of temperature-related limits on egg production (Aiken \& Waddy 1989, Waddy \& Aiken 1991) and growth (Ennis 1980). An alternative explanation is that the ventral surface of the abdomen, upon which females deposit and brood eggs, changes relative to body size with change in latitude. A larger abdomen area allows for larger egg masses (Templeman 1936, Atema \& Voigt 1995). In Nova Scotia coastal regions (MacCormack \& DeMont 2003), the scaling factor of abdomen area with carapace length varied with region. Estimates of the scaling of abdomen area with body size are needed over a wider latitudinal range to evaluate this explanation.

The major impediments to evaluating geographic variation in size-fecundity relationships to date have been the confounding effects of developmental stages on estimates of egg count (Ennis 1981), the discrepancy in size range among locations, and the poor fit of models (low $\mathrm{r}^{2}$ values) at some locations (Waddy \& Aiken 1991). Sampling methods and timing of studies have been similar in published studies of lobster fecundity since 1980. Validation of counting methods in these studies produced a mean error of less than $\pm 2.0 \%$. Eggs were removed at similar times near the end of the incubation period, May-June (Ennis 1981, Campbell \& Robinson 1983, Estrella \& Cadrin 1995). To obtain comparisons with similar egg developmental stages, parameter estimation was restricted to samples obtained during the spring (April-June), with the exception of the Bay of Fundy. Additionally, large size ranges were used to eliminate the confounding effects that small size ranges have on estimates of parameters $a$ and $b$. Finally, results in the present study had high $\mathrm{r}^{2}$ values, ranging from 0.88 to 0.99 .

Campbell \& Robinson (1983) evaluated the differences in the size-fecundity relationships of Homarus americanus in 3 maritime regions: eastern Nova Scotia, the Bay of Fundy and the Northumberland Strait. Their analysis revealed no significant differences in the relationships, and the data were condensed into a single equation used in maritime stock assessments (e.g. Lanteigne et al. 1998). However, the size ranges for each location were narrow, spanning only $40 \mathrm{~mm} \mathrm{CL}$, and large size ranges are needed to accurately evaluate size-fecundity relationships (Estrella \& Cadrin 1995). Our latitude model was not based on small size ranges at any one location. The predictive power of the 2 components of the latitude model for the 3 maritime locations increased substantially (Table 4) over those originally presented by Campbell \& Robinson (1983), where the predictive power is the ability of a size-fecundity (Table 3 ) equation to accurately estimate fecundity. The general latitude model and the published equations were found to have similar overall bias in estimating fecundity (Table 4). However, the general latitude model is applicable for any one location throughout the species range, whereas the published equations are location specific, and are not scalable to beyond the study area.

\section{Biases in analysis}

Our study suggests that a narrow range in body size has more influence on the estimates of sizefecundity parameters $a$ and $b$ than a small sample size. Both Lark Harbour and Barr'd Harbour had small sample sizes $(n=12)$, but had a wide range of carapace lengths, spanning over $60 \mathrm{~mm}$, and had high $\mathrm{r}^{2}$ values of approximately 0.98 . The limited influence that a small sample size had on estimates of parameters $a$ and $b$ was largely due to the influence that small and large values of the explanatory variable (in this case carapace length) had on the parameter estimates. Log transformation of data amplifies this overestimation, because small values of the response variable will have greater influence than large values on parameters obtained by fitting a linear equation to the logged data (Packard \& Boardman 2009). Log transformations had an average bias of $5.20 \%$ when estimated fecundity was used, whereas nonlinear regression on the raw data showed an average bias of only $4.41 \%$ (Table 4 ). Our results show that good estimates of the sizefecundity relationship in this species can be obtained by carrying out nonlinear regression on a small number of individuals spread over the widest possible range in body size.

The fishery for Homarus americanus currently has a total of 48 (Canada) and 6 (USA) different management zones. Within this range, 13 size-fecundity rela- 
tionships (Factor 1995) were available for use. The applicability of these size-fecundity relationships in zones with no estimate will be unknown. The choice of which relationship to use is ambiguous; possibilities include use of the closest estimate by distance, the average of the 2 closest estimates, or some other criterion. Our large-scale model provides a firstorder estimate based on all of the available data for the species. This estimate is consistent with what is known of the biology of the species.

Our results are of general applicability to management of Homarus americanus at locations where estimates of vital rates have not been developed. We show that a general model can be developed from location-specific estimates. The model that we developed was consistent with the biology of the species, strengthening its applicability to environmental decision-making in the context of management and conservation.

Our experience in applying recent advances in estimation techniques points at the need for publicly available data archives. Parameter estimates alone, even supported by adequate information on sample size, body size range and an estimate of variability on the biased estimate of the parameter $b$, would not have been sufficient to make estimates free of the bias due to $\log$ transformation. Adequate public archival of data allows updating of parameter estimates from new studies. It also allows development of general models based on new knowledge of the biology that governs vital rates such as fecundity and mortality. The problem of scale in ecology is that demographic rates such as mortality and offspring production do not necessarily scale in a 1:1 fashion from local measurement to the scale of management areas, stocks or populations. We found that annual egg release per gravid female was related to latitude in a linear fashion. Consequently, fecundity can be estimated at any spatial scale by taking the fecundity at the latitudinal midpoint of a region defined by north and south boundaries.

Acknowledgements. First and foremost, we thank Memorial University and the Natural Sciences and Engineering Research Council of Canada (NSERC) for providing funding for this research. We are indebted to Dr. Steve Cadrin and Dr. Bruce Estrella from the Massachusetts Department of Fisheries, Wildlife and Environmental Law Enforcement, Division of Marine Fisheries, who provided us with the data set necessary to complete the research. Gratitude is extended to Kate Wilke for her help in gathering data. Special thanks to Dr. Ian Fleming and Dr. Patrick Gagnon for their advice. We especially thank fishermen Charles Riles, Loomis Way and Allan Sheppard for providing their boats and gear to aid in the gathering of the data.

\section{LITERATURE CITED}

Aiken DE, Waddy SL (1980) Maturity and reproduction in the American lobster. Can Tech Rep Fish Aquat Sci 932: 60-71

Aiken DE, Waddy SL (1989) Interactions of temperature and photoperiod in the regulation of spawning by American lobster, Homarus americanus. Can J Fish Aquat Sci 46: $145-148$

Atema J, Voigt R (1995) Behaviour and sensory biology. In: Factor JR (ed) Biology of the lobster Homarus americanus. Academic Press, San Diego, CA

ASMFC (Atlantic States Marine Fisheries Commission) (2009) American lobster stock assessment report for peer review. Stock Assessment Report 09-01. ASFMC, Washington, DC

Attard J, Hudon C (1987) Embryonic development and energetic investment in egg production in relation to size of female lobster (Homarus americanus). Can J Fish Aquat Sci 44:1157-1164

Campbell A, Robinson DG (1983) Reproductive potential of three American lobster (Homarus americanus) stocks in the Canadian Maritimes. Can J Fish Aquat Sci 40: 1958-1967

Daniel PC, Bayer RC, Waltz C (1989) Egg production of v-notched American lobsters (Homarus americanus) along coastal Maine. J Crustac Biol 9:77-82

Ennis GP (1980) Recent and current research on lobster growth in the wild. Can Tech Rep Fish Aquat Sci 932: $10-15$

Ennis GP (1981) Fecundity of the American lobster, Homarus americanus, in Newfoundland waters. Fish Bull 79: 796-800

Estrella BT, Cadrin SX (1995) Fecundity of the American lobster (Homarus americanus) in Massachusetts coastal waters. ICES J Mar Sci Symp 199:61-72

Factor JR (1995) Biology of the lobster Homarus americanus. Academic Press, San Diego, CA

FRCC (Fisheries Resource Conservation Council) (2007) Sustainability framework for Atlantic lobster 2007. Report to the Ministers of Fisheries and Oceans. FRCC, Ottawa

Herrick FH (1896) The American lobster: a study of its habits and development. Bull US Fish Comm 15:1-252

Lanteigne M, Comeau M, Mallet M, Robichaud G, Savoie F (1998) The American lobster, Homarus americanus in the southern Gulf of St. Lawrence (lobster fishing areas 23, 24, 25, 26A, and 26B). Fisheries and Oceans Canada Report no. 98/123. DFO, Ottawa

MacCormack TJ, DeMont ME (2003) Regional differences in allometric growth in Atlantic Canadian lobster (Homarus americanus). J Crustac Biol 23:258-264

Motulsky HJ, Christopoulos A (2004) Fitting models to biological data using linear and nonlinear regression: a practical guide to curve fitting. Oxford University Press, Oxford

> Packard GC (2009) On the use of logarithmic transformations in allometric analyses. J Theor Biol 257:515-518

> Packard GC, Boardman TJ (2008) Model selection and logarithmic transformation in allometric analysis. Physiol Biochem Zool 81:496-507

> Packard GC, Boardman TJ (2009) A comparison of methods for fitting allometric equations to field metabolic rates of animals. J Comp Physiol B 179:175-182

Perkins HC (1971) Egg loss during incubation from offshore northern lobsters (decapoda: Homaridae). Fish Bull 
69:451-453

Saila SB, Flowers JM, Hughes JT (1969) Fecundity of the American lobster, Homarus americanus. Trans Am Fish Soc 98:537-539

Smith RJ (1980) Rethink allometry. J Theor Biol 87:97-111

Smith RJ (1984) Allometric scaling in comparative biology: problems of concept and method. Am J Phys Reg Int Comp Phys 246:152-160

Smith JR (1993) Logarithmic transformation bias in allometry. Am J Phys Anthropol 90:215-228

Squires HJ (1970) Lobster (Homarus americanus) fishery and ecology in Port au Port Bay, Newfoundland, 1960-65. Proc Natl Shellfish Assoc 60:22-39

Editorial responsibility: Romuald Lipcius, Gloucester Point, Virginia, USA
Squires HJ, Ennis GP, Tucker GE (1974) Lobsters of the northwest coast of Newfoundland, 1964-67. Proc Natl Shellfish Assoc 64:16-27

Templeman W (1936) Local differences in the life history of the lobster Homarus americanus) on the coast of the maritime provinces of Canada. J Biol Board Can:41-87

Waddy SL, Aiken DE (1991) Egg production in the American lobster, Homarus americanus. In: Wenner A, Kuris A (eds) Crustacean egg production. Crustaceans Issue 7th edn. A. A. Balkema, Brookfield, WI, p. 267-290

Zar JH (1968) Calculation and miscalculation of the allometric equation as a model in biological data. Bioscience 18: 1118-1120

Submitted: January 17, 2011; Accepted: July 26, 2011

Proofs received from author(s): October 1, 2011 